\title{
NUMERICAL ESTIMATION OF HULL HYDRODYNAMIC DERIVATIVES IN SHIP MANEUVERING PREDICTION
}

Radosław Kołodziej*

Maritime Advanced Research Centre, Gdańsk, Poland

Gdańsk University of Technology, Poland

Pawel Hoffmann

Maritime Advanced Research Centre, Gdańsk, Poland

*Corresponding author: radoslaw.kolodziej@cto.gda.pl (R. Kolodziej)

\section{ABSTRACT}

Prediction of the maneuvering characteristics of a ship at the design stage can be done by means of model tests, computational simulations or a combination of both. The model tests can be realized as a direct simulation of the standard maneuvers with the free running model, which gives the most accurate results but is also the least affordable, as it requires a very large tank or natural lake, as well as the complex equipment of the model. Alternatively, a captive model test can be used to identify the hydrodynamic characteristics of the hull, which can be used to simulate the standard maneuvers with the use of dedicated software. Two types of captive model tests are distinguished: circular motion tests (CMT) and planar motion mechanism tests (PMM). The paper presents an attempt to develop a computational method for ship maneuverability prediction in which the hydrodynamic characteristics of the hull are identified by means of computational fluid dynamics (CFD). The CFD analyses presented here directly simulate the circular motion test. The resulting hull characteristics are verified against the available literature data, and the results of the simulations are verified against the results of free running model tests. Reasonable agreement shows the large potential of the proposed method.

Keywords: Captive model tests,CFD tools in maneuvering prediction,MOERI Container ship (KCS),Hull hydrodynamic derivatives,Mathematical model of ship motion

\section{INTRODUCTION}

In the literature, there are numerous algorithms regarding the simulation of ship planar motion. One of them, which has successfully been used for different types of vessels and propulsions [1] [2] [3], was first introduced by the Mathematical Modeling Group (MMG). The presented model uses two corresponding coordinate systems. The forces acting on the ship are calculated in reference to a ship-fixed coordinate system, which is then transformed into an Earthfixed coordinate system.

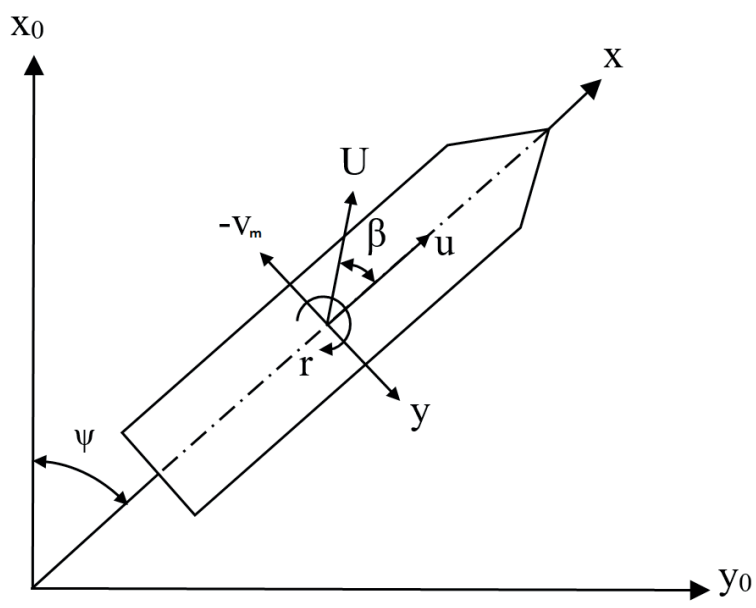

Fig. 1. Coordinate systems 
As a result, the following equations are obtained:

$$
\begin{aligned}
& \mathrm{F}_{\mathrm{x}}=\left(\mathrm{m}+\mathrm{m}_{\mathrm{x}}\right) \dot{\mathrm{u}}-\left(\mathrm{m}+\mathrm{m}_{\mathrm{y}}\right) v_{\mathrm{m}} r-\mathrm{mx}_{\mathrm{G}} \mathrm{r}^{2} \\
& \mathrm{~F}_{\mathrm{y}}=\left(\mathrm{m}+\mathrm{m}_{\mathrm{y}}\right) \dot{v}_{m}+\left(\mathrm{m}+\mathrm{m}_{\mathrm{x}}\right) \mathrm{ur}+\mathrm{mx}_{\mathrm{G}} \dot{r}_{m} \\
& \mathrm{~N}_{\mathrm{z}}=\left(\mathrm{I}_{\mathrm{zG}}+\mathrm{mx}_{\mathrm{G}}{ }^{2}+\mathrm{J}_{\mathrm{z}}\right) \dot{r}+\mathrm{mx}_{\mathrm{G}}\left(\dot{v}_{m}+\mathrm{ur}\right)
\end{aligned}
$$

where $\mathrm{m}$ is the mass of the ship, $\dot{v}_{m}$ denotes the ship's lateral speed at midship, $u$ is the longitudinal ship's speed, $r$ is the yaw rate, $x_{G}$ is the longitudinal coordinate of the center of gravity of the ship and $\mathrm{I}_{z \mathrm{G}}$ is the moment of inertia of the ship around the center of gravity. The $\mathrm{m}_{\mathrm{x}}, \mathrm{m}_{\mathrm{y}}$ and $\mathrm{J}_{\mathrm{z}}$ symbols stand for the added masses and added moment of inertia, which, for example, can be estimated based on Hooft's formula [4]. The $\mathrm{F}_{\mathrm{x}}, \mathrm{F}_{\mathrm{y}}$ and $\mathrm{N}_{\mathrm{z}}$ symbols represent, in order, the surge and sway forces as well as the yaw moment acting on the ship, which are a sum of the following components:

$$
\begin{gathered}
F_{x}=X_{H}+X_{P}+X_{R} \\
F_{y}=Y_{H}+Y_{R} \\
N_{z}=N_{H}+N_{R}
\end{gathered}
$$

The subscripts $\mathrm{H}, \mathrm{R}$ and $\mathrm{P}$ denote the forces and moments due to the hull, rudder and propeller, respectively.

\section{HULL FORCES}

The forces acting on a hull during maneuvering can be expressed, for practical purposes, in a non-dimensional form as follows [1]:

$$
\begin{gathered}
\mathrm{X}_{\mathrm{H}}=1 / 2 \rho \mathrm{L}_{\mathrm{PP}} \mathrm{dU}^{2} \mathrm{X}_{\mathrm{H}}^{\prime}\left(\beta, \mathrm{r}^{\prime}\right) \\
\mathrm{Y}_{\mathrm{H}}=1 / 2 \rho \mathrm{L}_{\mathrm{PP}} \mathrm{dU}^{2} \mathrm{Y}_{\mathrm{H}}^{\prime}\left(\beta, \mathrm{r}^{\prime}\right) \\
\mathrm{N}_{\mathrm{H}}=1 / 2 \rho \mathrm{L}_{\mathrm{PP}}{ }^{2} \mathrm{dU}^{2} \mathrm{~N}_{\mathrm{H}}^{\prime}\left(\beta, \mathrm{r}^{\prime}\right)
\end{gathered}
$$

where $\rho$ is the water density, $\mathrm{L}_{\mathrm{Pp}}$ is the length between perpendiculars, $\mathrm{d}$ stands for the ship draught and $\mathrm{U}$ is the ship velocity. The non-dimensional hull forces can now be expressed as polynomial functions using the drift angle $\beta$ and $\mathrm{r}^{\prime}=\mathrm{rL}_{\mathrm{pp}} / \mathrm{U}$ :

$$
\begin{gathered}
\mathrm{X}_{\mathrm{H}}^{\prime}=-\mathrm{R}_{0}^{\prime}+\mathrm{X}_{\beta \beta}^{\prime} \beta^{2}+\mathrm{X}_{\beta \mathrm{r}}^{\prime} \beta \mathrm{r}^{\prime}+\mathrm{X}_{\mathrm{rr}}^{\prime} \mathrm{r}^{\prime 2}+\mathrm{X}_{\beta \beta \beta \beta}^{\prime} \beta^{4} \\
\mathrm{Y}_{\mathrm{H}}^{\prime}=\mathrm{Y}_{\beta}^{\prime} \beta+\mathrm{Y}_{\mathrm{r}}^{\prime} \mathrm{r}^{\prime}+\mathrm{Y}_{\beta \beta \beta}^{\prime} \beta^{3}+\mathrm{Y}_{\mathrm{rrr}}^{\prime} \mathrm{r}^{\prime 3}+\left(\mathrm{Y}_{\beta \beta \mathrm{r}}^{\prime} \beta+\mathrm{Y}_{\beta \mathrm{rr}}^{\prime} \mathrm{r}^{\prime}\right) \beta \mathrm{r}^{\prime} \\
\mathrm{N}_{\mathrm{H}}^{\prime}=\mathrm{N}_{\beta}^{\prime} \beta+\mathrm{N}_{\mathrm{r}}^{\prime} \mathrm{r}^{\prime}+\mathrm{N}_{\beta \beta \beta}^{\prime} \beta^{3}+\mathrm{N}_{\mathrm{rrr}}^{\prime} \mathrm{r}^{\prime 3}+\left(\mathrm{N}_{\beta \beta \mathrm{r}}^{\prime} \beta+\mathrm{N}_{\beta \mathrm{rr}}^{\prime} \mathrm{r}^{\prime}\right) \beta \mathrm{r}^{\prime}
\end{gathered}
$$

The polynomial coefficients in equations (10), (11) and (12) are called hydrodynamic derivatives on maneuvering. There are various methods used in order to assess their value, such as captive model tests or numerical simulations. It has to be pointed out that the presented polynomial coefficients include added masses.

\section{PROPELLER FORCES}

The surge force generated by a working propeller is expressed as

$$
\mathrm{X}_{\mathrm{P}}=\left(1-\mathrm{t}_{\mathrm{P}}\right) \rho n_{P}^{2} D_{P}^{4} \mathrm{~K}_{\mathrm{T}}
$$

where $t_{p}$ is the thrust deduction factor, $\rho$ is the density of water, $n_{p}$ represents the propeller revolutions and $D_{p}$ is the propeller diameter. The propeller thrust open water efficiency $\mathrm{K}_{\mathrm{T}}$ is a function of the propeller advance ratio coefficient $\mathrm{J}_{\mathrm{p}}$, which can, for example, be calculated as a fourth order polynomial function:

$$
\mathrm{K}_{\mathrm{T}}=\mathrm{k}_{4} J_{P}^{4}+\mathrm{k}_{3} J_{P}^{3}+\mathrm{k}_{2} J_{P}^{2}+\mathrm{k}_{1} \mathrm{~J}_{\mathrm{P}}+\mathrm{k}_{0}
$$

$$
\mathrm{J}_{\mathrm{P}}=\frac{u\left(1-w_{P}\right)}{n_{P} D_{P}}
$$

The inflow of water to the propeller changes considerably during maneuvering because of the ship's drift angle. This phenomenon is difficult to capture, and many algorithms were proposed in order to do so [1] [5]. In this paper, the wake fraction coefficient of the propeller is calculated using the following formula:

$$
\mathrm{WP}=\mathrm{WP}_{0} e^{-4 \beta_{P}^{2}}
$$

$$
\beta_{\mathrm{P}}=\beta-x_{P}^{\prime} \mathrm{r}
$$

\section{RUDDER FORCES}

Hydrodynamic forces induced by the rudder during maneuvering can be calculated based on the rudder normal force according to the following equations:

$$
\begin{gathered}
\mathrm{X}_{\mathrm{R}}=-\left(1-\mathrm{t}_{\mathrm{R}}\right) \mathrm{F}_{\mathrm{N}} \sin \delta \\
\mathrm{Y}_{\mathrm{R}}=-\left(1+\mathrm{a}_{\mathrm{H}}\right) \mathrm{F}_{\mathrm{N}} \cos \delta \\
\mathrm{N}_{\mathrm{R}}=-\left(\mathrm{x}_{\mathrm{R}}+\mathrm{a}_{\mathrm{H}} \mathrm{x}_{\mathrm{H}}\right) \mathrm{F}_{\mathrm{N}} \cos \delta
\end{gathered}
$$




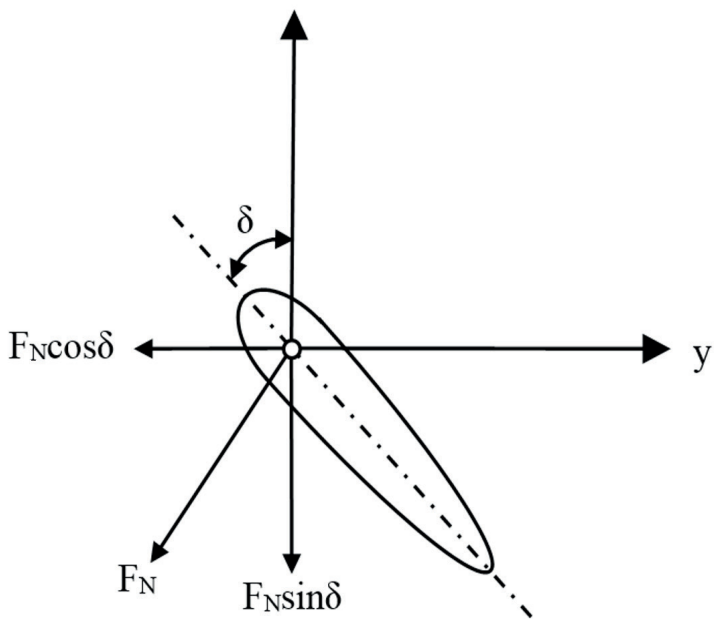

Fig. 2. Definition of rudder forces

The rudder normal force is expressed as

$$
\mathrm{F}_{\mathrm{N}}=0.5 \rho \mathrm{A}_{\mathrm{R}} \mathrm{f}_{\mathrm{a}} U_{R}^{2} \sin \alpha_{\mathrm{R}}
$$

Here, $A_{R}$ is the profile area of the moveable part of the rudder and $f_{a}$ stands for the normal force coefficient:

$$
\mathrm{f}_{\mathrm{a}}=\frac{6.13 \Lambda}{2.25+\Lambda}
$$

The $\Lambda$ coefficient in Eq. (22) is equal to $\frac{h_{R}^{2}}{A_{R}}$, where $h_{\mathrm{R}}$ is the rudder span. The effective angle of the ${ }^{A_{R}}$ water attack to the rudder $\alpha_{R}$ and the velocity of the water inflow to the rudder $\mathrm{U}_{\mathrm{R}}$ are calculated according to:

$$
\begin{gathered}
\alpha_{\mathrm{R}}=\delta-\tan ^{-1} \frac{v_{R}}{u_{R}} \\
\mathrm{U}_{\mathrm{R}}=\sqrt{u_{R}^{2}+v_{R}^{2}}
\end{gathered}
$$

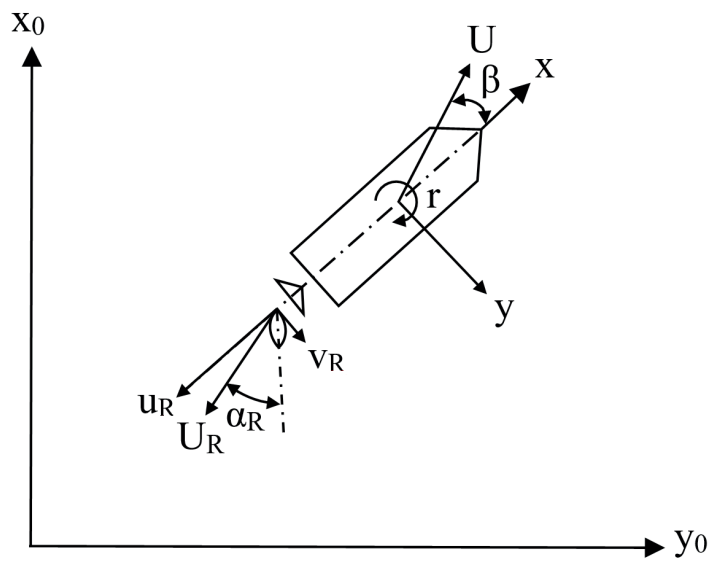

Fig. 3. Distribution of the water flow in the rudder area
The components of the water inflow to the rudder velocity are now calculated based on the following equations:

$$
\begin{gathered}
\mathrm{v}_{\mathrm{R}}=\mathrm{U} \gamma_{\mathrm{R} \pm}\left(\beta-\mathrm{r}^{\prime} l_{\mathrm{R}}\right) \\
\mathrm{u}_{\mathrm{R}}=\left(1-\mathrm{wP}_{\mathrm{P}}\right) \varepsilon \mathrm{u} \sqrt{\frac{D_{P}}{h_{R}}\left\{1+\kappa\left(\sqrt{1+\frac{8 K_{T}}{\pi J_{P}^{2}}}-1\right)\right\}^{2}+\left(1-\frac{D_{P}}{h_{R}}\right)} \\
\varepsilon=\frac{1-w_{R}}{1-w_{P}} \\
\kappa=\frac{0.55}{\varepsilon}
\end{gathered}
$$

where $\gamma_{R_{ \pm}}$is the flow straightening coefficient and $l_{R}^{\prime}$ is the effective longitudinal coordinate of the rudder position.

\section{INVESTIGATED SHIP}

The subject of this study is a bare hull container ship KCS (Kriso Container Vessel) equipped with a rudder horn. This is a popular test case because many model experiments and various CFD simulations have been done for this geometry, which is open to the public [6]. Table 1 shows the main ship particulars in real and 1:30.455 scales; the latter was used in both free running model tests and numerical simulations. In contradiction to the method presented by the MMG, the model was not equipped with a rudder and propeller during numerical simulations.

Tab. 1. Main ship particulars

\begin{tabular}{|l|c|c|c|c|}
\hline & Symbol & Unit & $\begin{array}{c}\text { Real } \\
\text { scale }\end{array}$ & $\begin{array}{c}\text { Model } \\
\text { scale }\end{array}$ \\
\hline Scale & $\lambda$ & {$[-]$} & $1: 1$ & $1: 30.455$ \\
\hline $\begin{array}{l}\text { Length between } \\
\text { perpendiculars }\end{array}$ & $\mathrm{L}_{\mathrm{pp}}$ & {$[\mathrm{m}]$} & 230.0 & 7.552 \\
\hline Breadth at waterline & $\mathrm{B}$ & {$[\mathrm{m}]$} & 32.2 & 1.057 \\
\hline Draught & $\mathrm{d}$ & {$[\mathrm{m}]$} & 10.8 & 0.355 \\
\hline Displacement volume & $\nabla$ & {$\left[\mathrm{m}^{3}\right]$} & 52030 & 1.842 \\
\hline Block coefficient & $\mathrm{C}_{\mathrm{B}}$ & {$[-]$} & 0.651 & 0.651 \\
\hline $\begin{array}{l}\text { Longitudinal coordinate of } \\
\text { the center of gravity }\end{array}$ & $\mathrm{x}_{\mathrm{G}}$ & {$[\mathrm{m}]$} & -3.4 & -0.111 \\
\hline $\begin{array}{l}\text { Radius of the gyration of the } \\
\text { ship around the center of } \\
\text { gravity (related to } \mathrm{L}_{\mathrm{pp}} \text { ) }\end{array}$ & $\mathrm{k}_{\mathrm{zz}}$ & {$[-]$} & 0.25 & 0.25 \\
\hline Propeller diameter & $\mathrm{D}_{\mathrm{p}}$ & {$[\mathrm{m}]$} & 7.9 & 0.259 \\
\hline $\begin{array}{l}\text { Propeller direction } \\
\text { of rotation }\end{array}$ & - & - & right & right \\
\hline $\begin{array}{l}\text { Rudder projected lateral } \\
\text { moveable area }\end{array}$ & $\mathrm{A}_{\mathrm{R}}$ & {$[\mathrm{m} 2]$} & 45.5 & 0.049 \\
\hline Rudder height & $\mathrm{hR}$ & {$[\mathrm{m}]$} & 9.9 & 0.325 \\
\hline Rudder turn rate & {$[\% / \mathrm{s}]$} & 2.32 & 12.8 \\
\hline
\end{tabular}




\section{NUMERICAL SIMULATION}

In this paper, simulations of circular motion tests (CMT) were conducted [7]. The tests were done for the constant ship's speed $\mathrm{U}_{0}=2.237 \mathrm{~m} / \mathrm{s}$ (equivalent to 24 knots in full scale). Prior to CMT tests, the propeller open water, resistance and propulsion model tests were done.

Tab. 2. Computational cases for the CMT

\begin{tabular}{|c|c|c|c|}
\hline & Symbol & Unit & Computational cases \\
\hline Rate of turn & $\mathrm{r}\left(\mathrm{r}^{\prime}\right)$ & ${ }^{\circ} / \mathrm{s}(-)$ & $2(0.118), 6(0.354), 8(0.471)$ \\
\hline Drift angle & $\beta$ & ${ }^{\circ}(\mathrm{rad})$ & $0, \pm 5(0.087), \pm 15(0.262), \pm 25(0.436)$ \\
\hline
\end{tabular}

The Computational Fluid Dynamics (CFD) analysis is carried out using the STAR-CCM+ solver with the Reynolds Averaged Navier-Stokes (RANSE) method. The Volume of Fluid model is used to simulate multiphase flow with a High-Resolution Interface Capturing (HRIC) scheme for solving the free surface. Turbulence modeling was executed with a "Realizable k-epsilon Two-layer" model. The hull movement was computed in the rectangular domain. The size of the domain was matched to contain the whole circular trajectory with an additional margin of at least one length of the model; the height of the domain was over two lengths of the model. For the movement simulation, the Overset Mesh technique was used. The computational domain consisted of two blocks: the smaller one, which contained the hull and its small vicinity, and the background region, in which the movement trajectory was contained. The domain boundary conditions were set up as walls with an additional function set up to damp the waves in its vicinity in order to prevent the waves' reflections inside the computational domain. The time step was equal to $2 \times 10^{-2} \mathrm{~s}$, and at least two full circulations were completed before stopping the simulation to achieve the convergence of the monitored forces. A visualization of the computational domain is shown in the figure below:

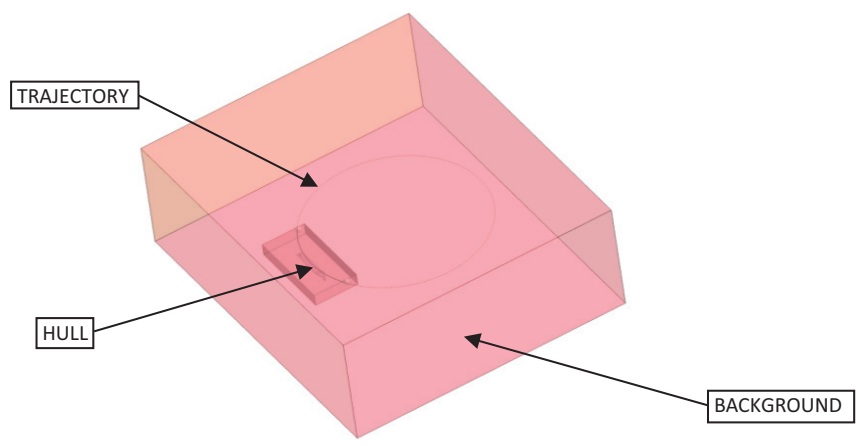

Fig. 4. Computational domain

Wave dumping was applied at the boundaries to prevent the reflections of the waves inside the computational domain. The running trim and sinkage of the hull were not taken into account in the computations. The dynamic hull motions were not taken into account in the computations to reduce the time of the computations. A mesh of the hexahedral type was used. The mesh, depending on the case, included up to
8000000 cells. The mesh on the hull and the mesh on the free surface are presented below:

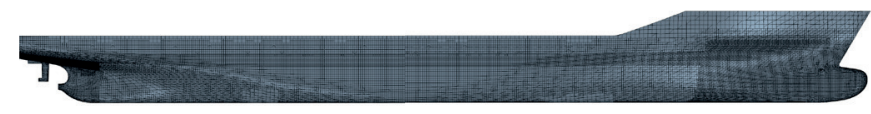

Fig. 5. Computational mesh on the KCS model surface

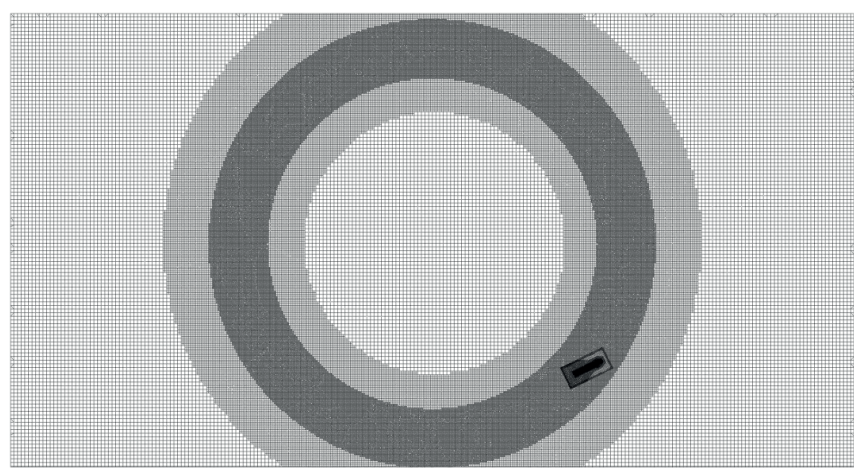

Fig. 6. Computational mesh on the free surface

\section{HULL HYDRODYNAMIC DERIVATIVES}

During the tests, longitudinal (X) and lateral (Y) forces as well as the moment induced by the hull $(\mathrm{N})$ were measured for different rates of the turn of the ship corresponding to the different drift angles. The results of numerical simulations in dimensionless form are presented in Table 3.

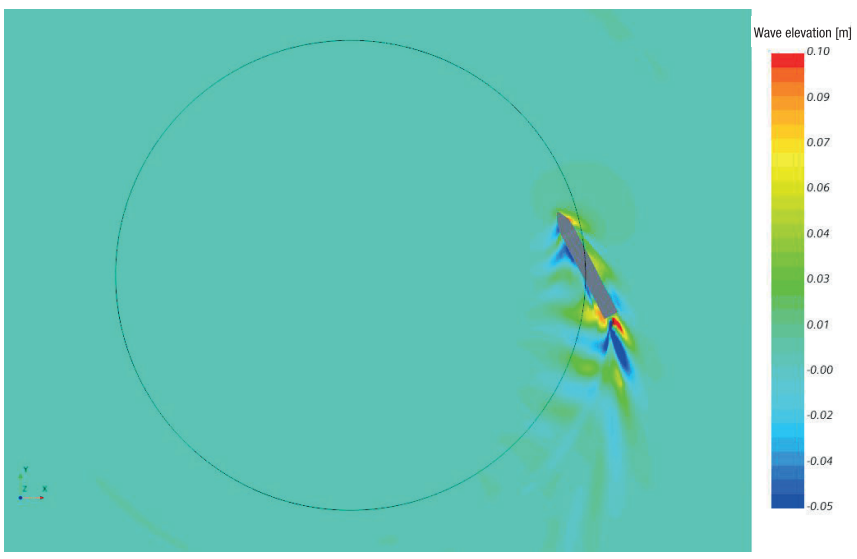

Fig. 7. Wave elevation and circular trajectory at $-25^{\circ}$ drift angle

As stated in equations (10-12), the forces $\mathrm{X}$ and $\mathrm{Y}$ and the moment $\mathrm{N}$ can be presented as dimensionless polynomial functions of the drift angle $\beta$ and the turn rate of the ship r'. In order to establish hydrodynamic derivatives of the hull, the surface was fitted on measured points using the least squares method, as shown in Fig. 8-10. The confidence bounds used for surface interpolation are equal to $\pm 5 \%$. Fig. 11 shows a comparison of the received results with captive model tests done by Japan's Society of Naval Architects and Ocean Engineers (JASNAOE) [8]. 
Tab. 3. Results of CFD simulations

\begin{tabular}{|c|c|c|c|c|c|c|c|c|c|}
\hline \multirow{3}{*}{$\begin{array}{c}\text { Drift angle } \\
{\left[^{\circ}\right]}\end{array}$} & \multicolumn{3}{|c|}{$\mathrm{X}_{\mathrm{H}}^{\prime}$} & \multicolumn{3}{|c|}{$\mathrm{Y}_{\mathrm{H}}^{\prime}$} & \multicolumn{3}{|c|}{$\mathrm{N}_{\mathrm{H}}^{\prime}$} \\
\hline & \multicolumn{9}{|c|}{ Rate of turn $[\%$ s] } \\
\hline & 2 & 6 & 8 & 2 & 6 & 8 & 2 & 6 & 8 \\
\hline-15 & -0.0128 & -0.0080 & -0.0057 & -0.0712 & -0.0941 & -0.1060 & -0.0384 & -0.0576 & -0.0660 \\
\hline-5 & -0.0132 & -0.0142 & -0.0137 & -0.0142 & -0.0243 & -0.0326 & -0.0149 & -0.0266 & -0.0326 \\
\hline 0 & -0.0133 & -0.0163 & -0.0172 & -0.0013 & -0.0018 & 0.0007 & -0.0036 & -0.0145 & -0.0216 \\
\hline 5 & -0.0149 & -0.0196 & -0.0213 & 0.0149 & 0.0227 & 0.0264 & 0.0058 & -0.0029 & -0.0090 \\
\hline 15 & -0.0190 & -0.0271 & -0.0305 & 0.0655 & 0.0754 & 0.0839 & 0.0238 & 0.0110 & 0.0042 \\
\hline 25 & -0.0220 & -0.0355 & -0.0412 & 0.1362 & 0.1546 & 0.1622 & 0.0425 & 0.0245 & 0.0139 \\
\hline
\end{tabular}

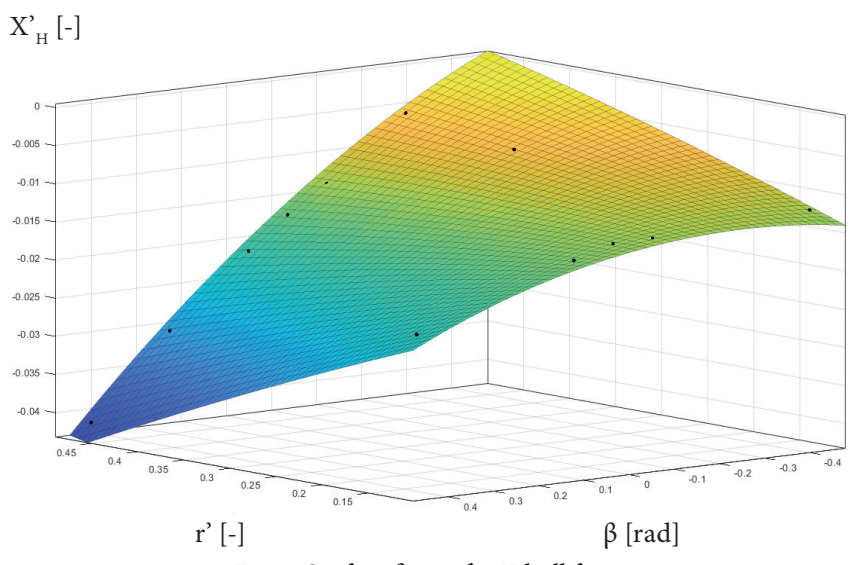

Fig. 8. Surface fitting for $X$ hull forces

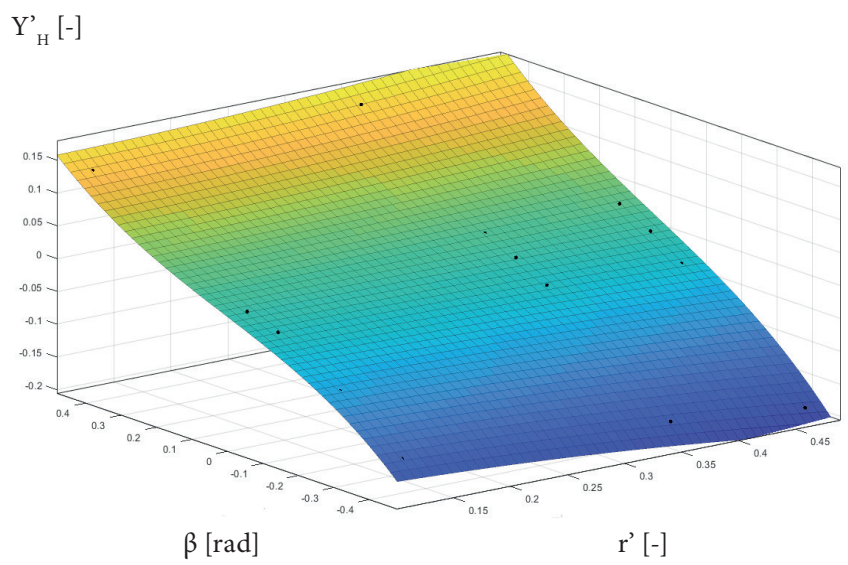

Fig. 9. Surface fitting for $Y$ hull forces

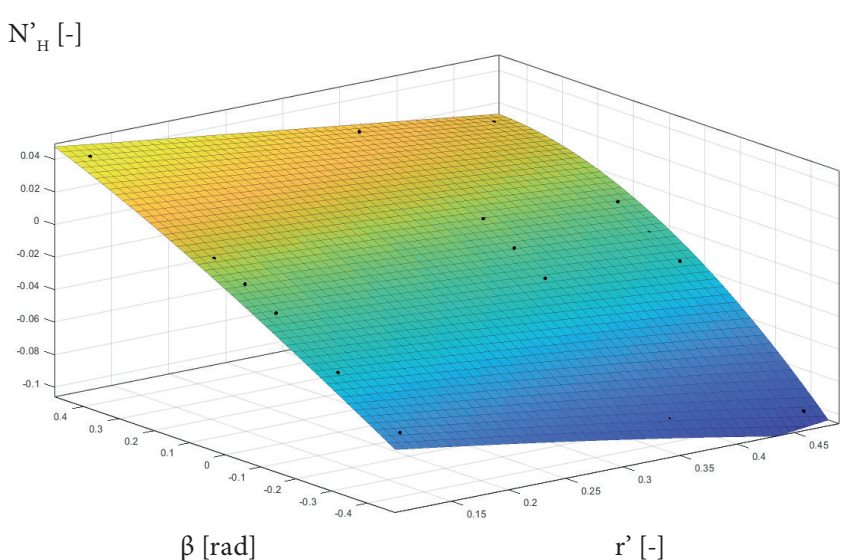

Fig. 10. Surface fitting for $N$ hull moments
Tab. 4. Hull hydrodynamic derivatives

\begin{tabular}{|c|c|c|c|c|c|}
\hline \multicolumn{6}{|c|}{$\mathrm{X}$ force } \\
\hline $\mathrm{R}_{0}^{\prime}$ & $\mathrm{X}_{\beta \beta}^{\prime}$ & $\mathrm{X}_{\beta \mathrm{r}}^{\prime}$ & $\mathrm{X}_{\mathrm{rr}}^{\prime}$ & \multicolumn{2}{|c|}{$X_{\beta \beta \beta \beta}^{\prime}$} \\
\hline \multicolumn{6}{|c|}{ CFD simulation } \\
\hline-0.0139 & -0.0032 & -0.0942 & -0.0134 & \multicolumn{2}{|c|}{0.0794} \\
\hline \multicolumn{6}{|c|}{ Captive model tests (JASNAOE) } \\
\hline-0.0139 & -0.0549 & -0.1084 & -0.0120 & \multicolumn{2}{|c|}{-0.0417} \\
\hline \multicolumn{6}{|c|}{$\mathrm{Y}$ force } \\
\hline $\mathrm{Y}_{\beta}^{\prime}$ & $\mathrm{Y}_{\mathrm{r}}^{\prime}$ & $\mathrm{Y}_{\beta \beta \beta}^{\prime}$ & $\mathrm{Y}_{\mathrm{rrr}}^{\prime}$ & $Y_{\beta \beta r}^{\prime}$ & $\mathrm{Y}_{\beta \mathrm{rr}}^{\prime}$ \\
\hline \multicolumn{6}{|c|}{ CFD simulation } \\
\hline 0.2526 & 0.0215 & 0.5779 & 0.0812 & -0.0383 & 0.5199 \\
\hline \multicolumn{6}{|c|}{ Captive model tests (JASNAOE) } \\
\hline 0.2252 & 0.0398 & 1.7179 & -0.0050 & -0.4832 & 0.8341 \\
\hline \multicolumn{6}{|c|}{$\mathrm{N}$ moment } \\
\hline $\mathrm{N}_{\beta}^{\prime}$ & $\mathrm{N}_{\mathrm{r}}^{\prime}$ & $\mathrm{N}_{\beta \beta \beta}^{\prime}$ & $\mathrm{N}_{\mathrm{rrr}}^{\prime}$ & $\mathrm{N}_{\beta \beta \mathrm{r}}^{\prime}$ & $\mathrm{N}_{\beta \mathrm{rr}}^{\prime}$ \\
\hline \multicolumn{6}{|c|}{ CFD simulation } \\
\hline 0.1141 & -0.0468 & -0.0596 & -0.0616 & -0.2749 & 0.0218 \\
\hline \multicolumn{6}{|c|}{ Captive model tests (JASNAOE) } \\
\hline 0.1111 & -0.0465 & 0.1751 & -0.0387 & -0.6167 & 0.0512 \\
\hline
\end{tabular}

The established hydrodynamic derivatives show considerable differences in comparison with the captive model tests presented by JASNAOE. Although the lower power coefficients, which have the biggest impact on the simulation, are a good match, the higher power coefficients, which have a lower impact, show large differences. The derivatives of correlated variables (like $\mathrm{Y}_{\beta \beta \mathrm{r}}{ }$ and $\mathrm{Y}^{\prime}{ }_{\beta \mathrm{rr}}$ ) that affect the growth rate of forces and the moment in the time domain diverge as well, which is understandable as they are also correlated with each other and are very sensitive to surface approximation. This, however, does not necessarily influence the simulations, as their general interaction can have a similar outcome, as proved in further paragraphs. 


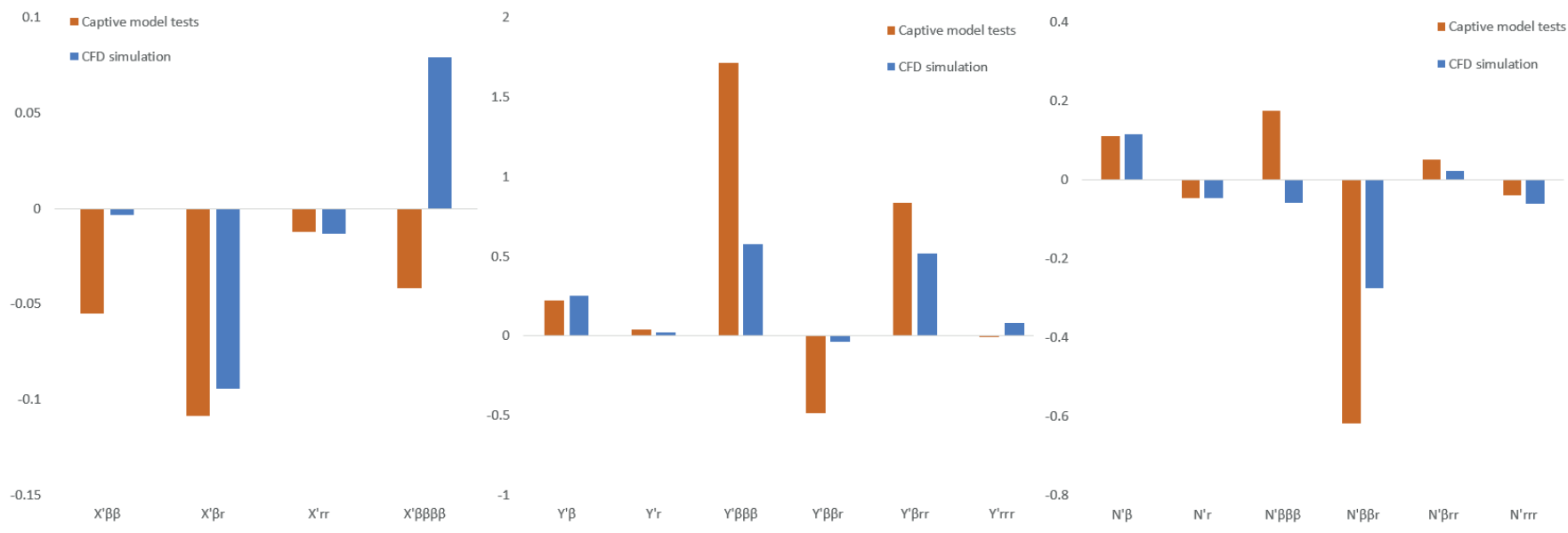

Fig. 11. Comparison of hydrodynamic derivatives received from CFD and captive model tests (JASNAOE)

\section{SIMULATION OF IMO STANDARD MANEUVERS}

The IMO Standards are based on the assumption that the maneuverability of ships can be evaluated from the characteristics of conventional trial maneuvers [9]. Model tests such as the turning circle and zigzag duplicate the full-scale trial maneuvers, and the results can be compared directly with the IMO criteria [10]. In this paper, simulations of turning and zigzag tests are performed based on data received from CFD simulations and captive model tests presented by JASNAOE, and they are then compared with free running model tests. The ODE4 fixed step solver was used to simulate the maneuvers using MATLAB Simulink software. It has to be pointed out that using different types of solvers does not significantly influence the simulation results. The inertia terms of the ship used in both cases are included along with parameters used for the calculation of propeller and rudder forces in Table 5 [11]. The comparison of 10/10 and 20/20 zigzag maneuvers is shown in Fig. 12-15, and the trajectories for the turning circle test for $\delta= \pm 35^{\circ}$ are presented in Fig. 16. Selected parameters for trial maneuvers are included in Table 6.

Tab. 5. Parameters used in simulations [11]

\begin{tabular}{|c|c|c|c|c|c|c|c|}
\hline $\mathrm{m}_{\mathrm{x}}^{\prime}$ & $\mathrm{m}_{\mathrm{y}}^{\prime}$ & $\mathrm{J}_{\mathrm{z}}^{\prime}$ & $\mathrm{t}_{\mathrm{p}}$ & $\mathrm{x}_{\mathrm{p}}^{\prime}$ & $\mathrm{t}_{\mathrm{R}}$ & $\mathrm{a}_{\mathrm{H}}$ & $\mathrm{x}_{\mathrm{H}}$ \\
\hline 0.013 & 0.138 & 0.006 & 0.179 & -0.491 & 0.161 & 0.448 & -0.444 \\
\hline $\mathrm{l}_{\mathrm{R}}^{\prime}$ & $\mathrm{w}_{\mathrm{P} 0}$ & $\mathrm{x}_{\mathrm{R}}^{\prime}$ & $\varepsilon$ & $\kappa$ & $\gamma_{\mathrm{R}+}$ & $\gamma_{\mathrm{R}-}$ & $\mathrm{f}_{\mathrm{a}}$ \\
\hline-0.751 & 0.274 & -0.500 & 0.944 & 0.583 & 0.237 & 0.395 & 2.998 \\
\hline
\end{tabular}

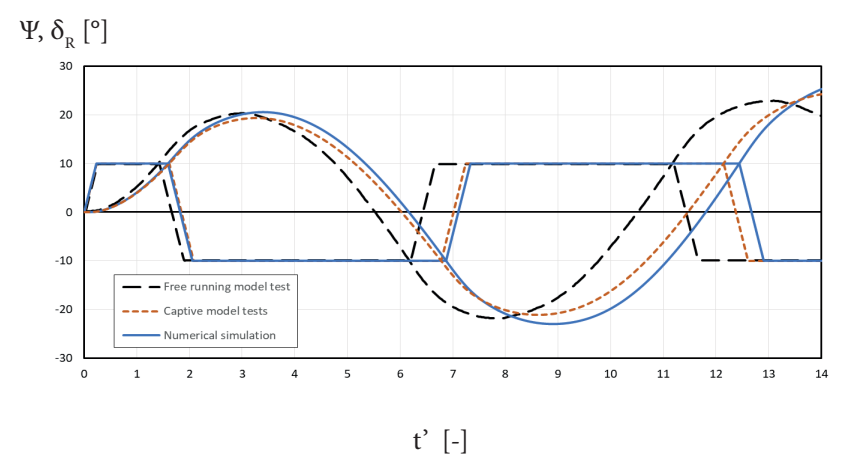

Fig. 12. Comparison of 10/10 zig-zag maneuvers, first turn to STBD

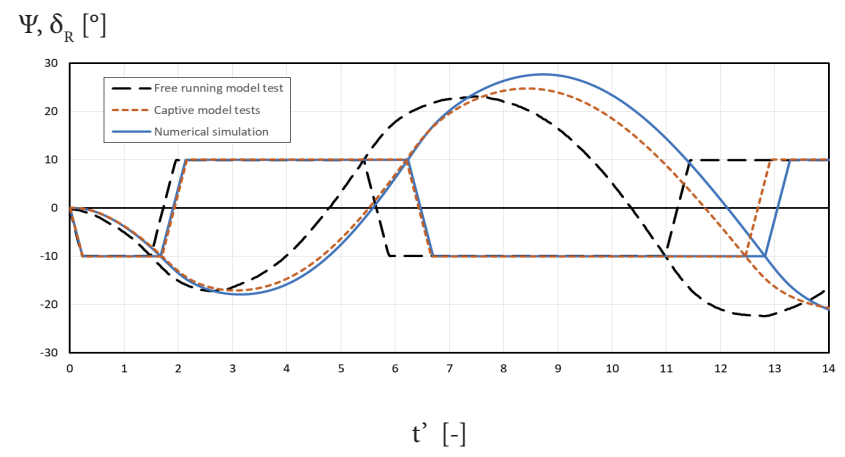

Fig. 13. Comparison of 10/10 zig-zag maneuvers, first turn to PS $\Psi, \delta_{\mathrm{R}}\left[^{\circ}\right]$

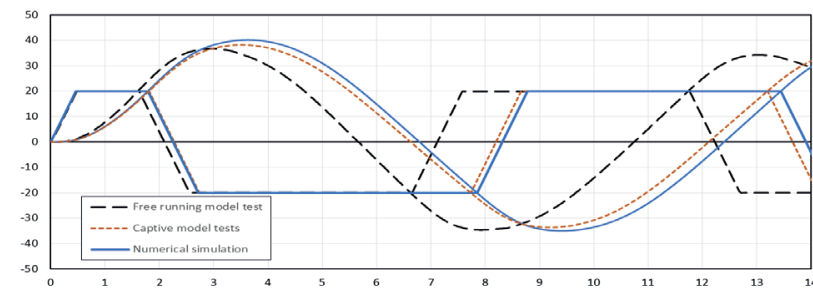

t' $[-]$

Fig. 14. Comparison of 20/20 zig-zag maneuvers, first turn to STBD 


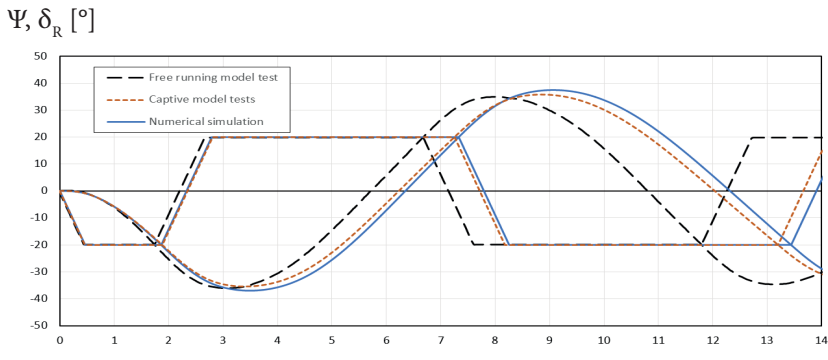

$t^{\prime}[-]$

Fig. 15. Comparison of 20/20 zig-zag maneuvers, first turn to PS

where the non-dimensional time $\mathrm{t}^{\prime}=\mathrm{t} \frac{U_{0}}{L_{P P}}$. $\mathrm{x} / \mathrm{L}_{\mathrm{pp}}[-]$

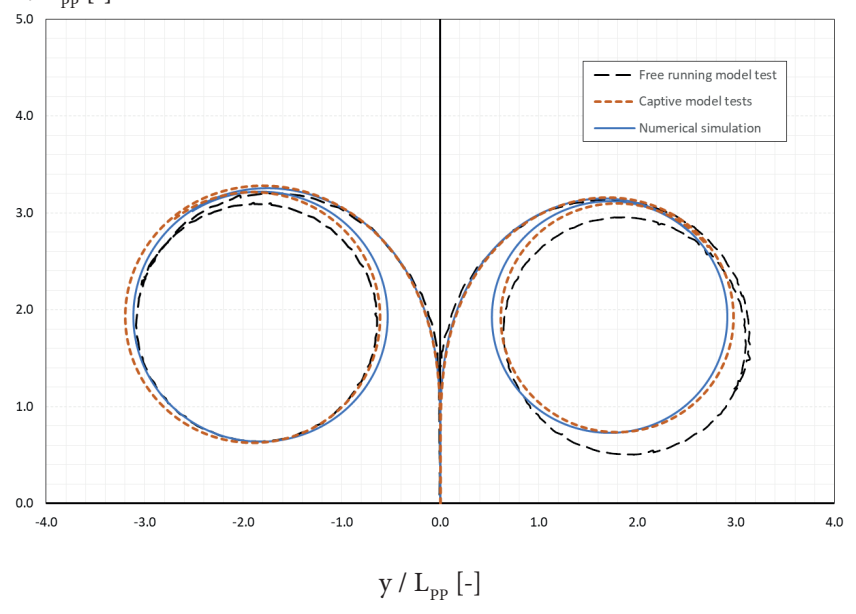

Fig. 16. Comparison of turning trajectories for $\delta= \pm 35^{\circ}$

Tab. 6. Comparison of selected maneuvering criteria parameters [9]

\begin{tabular}{|c|c|c|c|c|}
\hline Maneuver & Parameter & $\begin{array}{l}\text { Free } \\
\text { running } \\
\text { model } \\
\text { test }\end{array}$ & $\begin{array}{c}\text { Captive } \\
\text { model tests } \\
\text { (JASNAOE) }\end{array}$ & $\begin{array}{l}\text { Numerical } \\
\text { simulation }\end{array}$ \\
\hline \multirow{3}{*}{$\begin{array}{c}\text { zigzag } \\
10^{\circ} / 10^{\circ} \\
\text { (first turn to } \\
\text { STBD) }\end{array}$} & $t_{\mathrm{a}}^{\prime}$ & 1.4 & 1.6 & 1.7 \\
\hline & 1 st OSA & 10.3 & 9.3 & 10.6 \\
\hline & 2 st OSA & 11.7 & 11.1 & 13.0 \\
\hline \multirow{3}{*}{$\begin{array}{c}\text { zigzag } \\
10^{\circ} / 10^{\circ} \\
\text { (first turn to PS) }\end{array}$} & $t_{\mathrm{a}}^{\prime}$ & 1.6 & 1.7 & 1.7 \\
\hline & 1 st OSA & 7.0 & 7.1 & 7.9 \\
\hline & 2 st OSA & 13.4 & 14.8 & 17.7 \\
\hline \multirow{3}{*}{$\begin{array}{c}\text { zigzag } \\
20^{\circ} / 20^{\circ} \\
\text { (first turn to } \\
\text { STBD) }\end{array}$} & $t_{\mathrm{a}}^{\prime}$ & 1.6 & 1.8 & 1.8 \\
\hline & 1 st OSA & 15.8 & 17.2 & 19.0 \\
\hline & 2 st OSA & 14.8 & 13.0 & 14.4 \\
\hline \multirow{3}{*}{$\begin{array}{c}\text { zigzag } \\
20^{\circ} / 20^{\circ} \\
\text { (first turn to PS) }\end{array}$} & $t_{\mathrm{a}}^{\prime}$ & 1.8 & 1.9 & 1.9 \\
\hline & 1 st OSA & 16.1 & 14.6 & 16.7 \\
\hline & 2 st OSA & 14.9 & 15.1 & 16.0 \\
\hline \multirow{4}{*}{$\begin{array}{c}\text { turning } \\
35^{\circ} \mathrm{STBD}\end{array}$} & $A^{\prime} D$ & 3.1 & 3.1 & 3.1 \\
\hline & D'T & 3.1 & 3.0 & 2.9 \\
\hline & $\mathrm{D}_{\mathrm{C}} / \mathrm{L}_{\mathrm{pP}}$ & 2.4 & 2.4 & 2.5 \\
\hline & $\mathrm{U} / \mathrm{U}_{0}$ & 0.47 & 0.36 & 0.36 \\
\hline
\end{tabular}

\begin{tabular}{|c|c|c|c|c|}
\hline \multirow{2}{*}{ Maneuver } & Parameter & $\begin{array}{c}\text { Free } \\
\text { running } \\
\text { model } \\
\text { test }\end{array}$ & $\begin{array}{c}\text { Captive } \\
\text { model tests } \\
\text { (JASNAOE) }\end{array}$ & $\begin{array}{c}\text { Numerical } \\
\text { simulation }\end{array}$ \\
\hline \multirow{2}{*}{$\begin{array}{c}\text { turning } \\
35^{\circ} \mathrm{PS}\end{array}$} & $\mathrm{A}^{\prime} \mathrm{D}$ & 3.1 & 3.2 & 3.2 \\
\cline { 2 - 5 } & $\mathrm{D}^{\prime} \mathrm{T}$ & 3.0 & 3.2 & 3.1 \\
\cline { 2 - 5 } & $\mathrm{D}_{\mathrm{C}} / \mathrm{L}_{\mathrm{PP}}$ & 2.5 & 2.6 & 2.6 \\
\cline { 2 - 5 } & $\mathrm{U}^{\prime} \mathrm{U}_{0}$ & 0.45 & 0.38 & 0.38 \\
\hline
\end{tabular}

where $t_{\mathrm{a}}^{\prime}$ is the initial turning ability time, OSA stands for Overshoot angle, $\mathrm{A}_{\mathrm{D}}^{\prime}$ is the Advance, $\mathrm{D}_{\mathrm{T}}{ }_{\mathrm{T}}$ is the tactical diameter, $\mathrm{D}_{\mathrm{C}} / \mathrm{L}_{\mathrm{pP}}$ represent turning radius in reference to the length between perpendiculars and $\mathrm{U} / \mathrm{U}_{0}$ represent speed in reference to the approach speed.

\section{CONCLUSIONS}

The experimentally established values of hydrodynamic coefficients differ considerably from the values calculated with the use of regression formulas. This, however, does not seem to affect the final prediction of the maneuvers, as they show satisfying agreement in terms of practical purposes. It is assumed that the values of the hydrodynamic derivatives that show a large difference with regard to their origin method have a low impact on prediction, as the main discrepancies occur for coefficients of higher powers. The results of the predictions show a considerable difference in the drop of the speed of the ship, which means that the $\mathrm{X}$ forces are overestimated. What is more the underestimation of $\mathrm{N}$ moments can be noticed as rate of turn of ship (fig. 17) is lower for CFD and captive model tests in comparison to the free running model tests. This leads to conclusion that the $\mathrm{Y}$ forces are underestimated as well as turning radiuses are similar in each case. Other papers concerning this topic has provided similar results which further backs this theory [12].

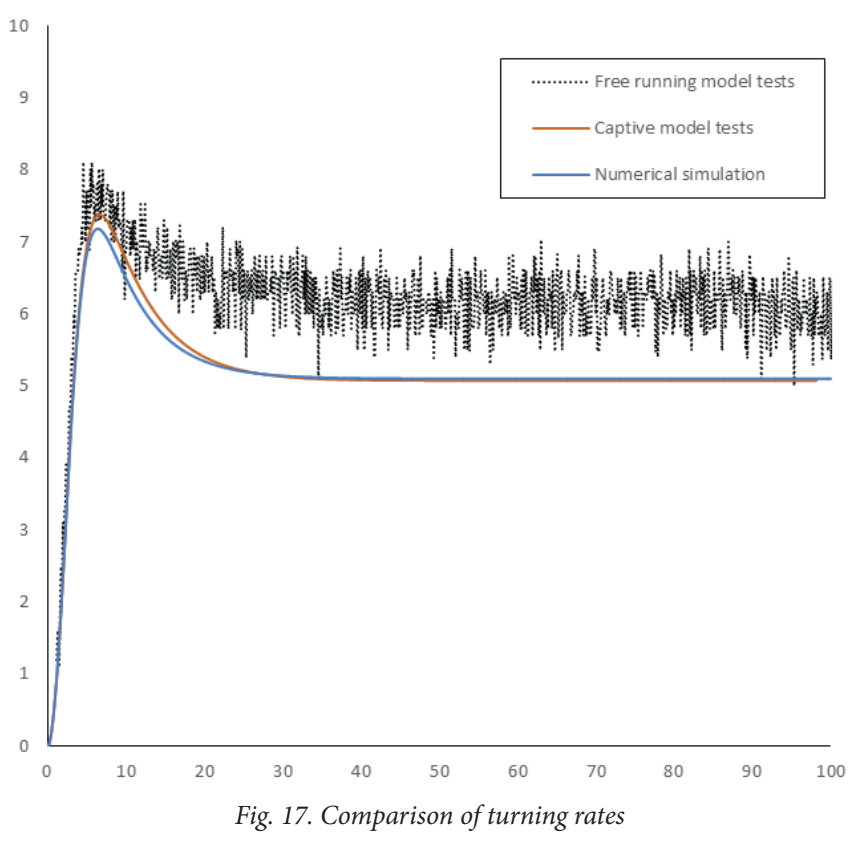




\section{ACKNOWLEDGMENT}

This paper has been elaborated within the framework of the internal research and support of the Maritime Advanced Research Centre (CTO S.A) in 2020.

\section{REFERENCES}

1. H. Yasukawa and Y. Yoshimura, "Introduction of MMG standard method for ship maneuvering predictions", Journal of Marine Science and Technology, 2015, (DOI: 10.1007/s00773-014-0293-y).

2. M. Reichel, "Prediction of maneuvering abilities of 10000 DWT pod-driven coastal tanker", Ocean Engineering, vol. 136, pp. 201-208, 2017, (DOI: 10.1016/j. oceaneng.2017.03.025).

3. K. Dai and Y. Li "Manoeuvring prediction of KVLCC2 with hydrodynamic derivatives generated by a virtual captive test”, Polish Maritime Research 4 (104) 2019 Vol. 26; pp. 16-26 (DOI: 10.2478/pomr-2019-0062).

4. J. P. Hooft and J. Pieffers, "Maneuverability of frigates in waves”, Marine Technology, vol. 25, no. 4, pp. 262-271, 1988, (DOI: 10.5957/mt1.1988.25.4.262 ).

5. H. Lee and S. Shin, "The prediction of ship's maneuvering performance in initial design stage", Hyundai Maritime Research Institute, Elsevier Science B. V., 1998, (DOI: 10.1016/s0928-2009(98)80205-9).

6. Y. Yoshimura, M. Ueno, and Y. Tsukada, "Analysis of steady hydrodynamic force components and prediction of maneuvering ship motion with KVLCC1, KVLCC2 and KCS”, Workshop on verification and validation of ship maneuvering simulation method, Workshop Proceedings, vol. 1, Copenhagen, pp. E80-E86, SIMMAN 2008.

7. M. Ueno, Y. Yoshimura, Y. Tsukada, and H. Miyazaki, "Circular motion tests and uncertainty analysis for ship maneuverability", The Japan Society of Naval Architects and Ocean Engineers, 2009, (DOI: 10.1007/s00773-009-0065-2).

8. Report of the research committee on the standardization of mathematical models for ship maneuvering predictions (P-29), The Japan Society of Naval Architects and Ocean Engineers, 2013.

9. IMO Res MSC: Standards for Ship Maneuverability, vol.37, no. 76, 2002.

10. IMO MSC/Circ.: Explanatory Notes to the Standards for Ship Maneuverability, 2002.
11. R. Kołodziej, "Numerical approach to assessment of maneuvering properties of ship with a single propeller", Coastal, Offshore and Ocean Conference, 2019.

12. B. Mei, L. Sun, G. Shi, X. Liu, "Ship maneuvering prediction using grey box framework via adaptive RM-SVM with minor rudder" Polish Maritime Research 3 (103) 2019 Vol. 26; pp. 115-127 (DOI: 10.2478/pomr-2019-0052).

\section{CONTACT WITH THE AUTHORS}

\author{
Radosław Kołodziej \\ e-mail: radoslaw.kolodziej@cto.gda.pl \\ Centrum Techniki Okrętowej S.A., \\ Szczecińska 65, 80-396 Gdańsk, \\ Politechnika Gdańska, \\ Gabriela Narutowicza 11/12, 80-233 Gdańsk, \\ Poland \\ Pawel Hoffmann \\ e-mail:pawel.hoffmann@cto.gda.pl \\ Centrum Techniki Okrętowej S.A., \\ Szczecińska 65, 80-396 Gdańsk, \\ POLAND
}

